
\title{
R Research S Surare \\ Cervicogenic Headache and the Relationship Between the Position and Movement of the Upper Cervical Spine and Dura
}

Rob Sillevis ( $\square$ rsillevis@fgcu.edu )

Florida Gulf Coast University https://orcid.org/0000-0003-2245-0996

Eric Shamus

Florida Gulf Coast University

Karen Wyss

Integrated Therapy Practice

Research article

Keywords: Cervicogenic headache, atlas positional fault, slump test, upper limb tension test, straight leg raise, neural tension

Posted Date: May 28th, 2020

DOI: https://doi.org/10.21203/rs.3.rs-31086/v1

License: (c) (i) This work is licensed under a Creative Commons Attribution 4.0 International License. Read Full License 


\section{Abstract}

Background: It has been demonstrated that cervicogenic headaches (CGH) is caused by dysfunction of the upper cervical spine. Due the soft tissue connection between muscle, cervical fascia and dura, this region might contribute to the development of CGH's. This study evaluated if subjects with CGH have concurrent neural tension signs. The secondary aim of this study was to investigate if there is a correlation between the position of atlas and mobility of atlantoaxial joint in those experiencing cervicogenic headaches compared to a healthy control group.

Methods: A convenience sample of 60 subjects were recruited for this study. Each subjected completed self-reported outcome measures, after which the passive neck flexion rotation test, upper limb tension test (ULTT), slump test, and straight leg raise test (SLR) was performed by the physical therapist.

Outcomes: There was a significant difference in the passive atlantoaxial rotation to the right between the CGH and the control group $\mathbf{p}=\mathbf{0 . 0 2 5}$. There was a no statistically significance in left rotation. There was no significant relationship between CGH and the ULTT, slump ad SLR with $P>0.05$. The position of atlas was significantly related with $\mathrm{CGH}$ with $\mathrm{P}<0.001$ and position of atlas was significantly related to $\mathrm{AA}$ motion with $p<0.001$

Discussion: The results of this study demonstrate that there is a direct relationship between the position of atlas, unilateral restriction in AA rotation, and the presence of CGH's. The presence of fascial connections between structures of the high cervical spine and the dura motion could result in dural tension and should be considered by physical therapists when managing patients with $\mathrm{CGH}$. The use of the ULTT, Slump test, and SLR test do not appear beneficial identifying those with CGH.

\section{Introduction}

Neck disorders are common and create a large burden on society. The burden to the healthcare system is more than 50 billion dollars each year.(1,2) Additionally, neck related disorders can lead to a reduced ability or inability to work, and reduced work-related productivity.(3-5) Individuals with dysfunctions originating in the cervical spine can present with a large variety of symptomatic regions including: the neck, occipital and facial areas, shoulder, arm, and scapulothoracic region. Any structure in the neck including the intervertebral disc, ligaments, muscles, facet joints, dura, and nerve roots can contribute to the pain. $(6,7)$ Cervicogenic headache $(\mathrm{CGH})$ is an example of a condition that is caused by dysfunction in the cervical spine. Cervicogenic headache has been defined by the International Headache Society as "pain, referred from a source in the neck and perceived in 1 or more regions in the head and/ or face".(8) The prevalence of CGH has been reported to range from $15-20 \%$ of all headaches,(9) and around $4 \%$ of the general population experiences $\mathrm{CGH}^{\prime}$. $(10,11)$ It typically presents as an unilateral headache that can spread to the frontal, temporal and orbital regions, neck, shoulder, and arm. Although the exact mechanism remains elusive, it appears that CGH is the result of mechanical dysfunction in the upper cervical spine.(11-13) A possible rationale for the development of CGH is the direct relationship between 
the trigeminal nerve and the spinal nerves $\mathrm{C} 1$ through $\mathrm{C} 3$ at the trigeminocervical nucleus. $(14,15)$ The trigeminocervical nucleus is functionally continuous with the dorsal horns of the upper cervical segments therefore nociceptive signals can converge with the trigeminal second order neuron. This could result in a perception of radiating pain via the ophthalmic branch of the trigeminal nerve.(14-16)

Another rationale for the development of CGH might be related to the fact that the motion of the suboccipital region is controlled by several groups of both smaller and larger muscle groups. It has been previously demonstrated that abnormal cervical functioning will change the proprioceptive awareness coming from mechanoreceptive neurons in this region.(17) There is an exceptionally high density of mechanoreceptors in the suboccipital muscles located in the posterior upper cervical region.(17) With cervical dysfunction, proprioception may be impeded as a result of pain, swelling, trauma, and/or muscular fatigue. In addition to this relationship between muscle and proprioception, Scali et al(18) and Pontel et al(19) demonstrated that fascial tissues originating from the Rectus Capitis Posterior Minor, Rectus Capitis Posterior Major, and the Obliquus Capitis Inferior can be identified in the space between the $\mathrm{C} 1$ and $\mathrm{C} 2$ vertebrae. These fascial tissue structures have been referred to as the "myodural bridges". Between the arches of $\mathrm{C} 1$ and $\mathrm{C} 2$, the myodural bridges merge with the meningovertebral ligaments and crosses the epidural space, inserting into the posterior aspect of the dura mater. It has been proposed that these myodural bridges are meant to protect the cervical dura during motion and prevent compression of the cord.(18) The significance of the myodural bridge is that there is a direct anatomical connection between the muscle, cervical fascia, and the central nervous system. This could possibly explain the phenomenon of neurotension often identified by clinicians when treating patients with headaches and cervical related dysfunctions.(20-22)

Muscular impairment (dysfunctions) has been identified as possible contributing factor for the development of $\mathrm{CGH} .(23,24)$ The upright position in humans results in loading of the cervical spine due to the weight of the head. This can leave the neck susceptible to progressive, degenerative changes over time. These changes will result in mechanical compression due to an increased cervical curve and a posterior rotation of the head on the neck. The ventral ramus of the upper cervical spine innervates the prevertebral muscles along with the facet capsules of $\mathrm{C} 2$ and C3.(25) The median atlantoaxial joint and its ligaments, the posterior cranial fossa and dura mater, the trapezius, and sternocleidomastoid (SCM) are supplied by C1-C3 nerves. ${ }^{(6,25)}$ Muscles will adapt to both the position they are placed in and the functions they have to perform. Patients with $\mathrm{CGH}$ often present with forward head posture that leads to an upper cross muscle syndrome (UCMS).(26) The upper cross muscle syndrome is characterized by the simultaneous development of both weak and short muscles. Weakness and endurance deficits in the deep neck flexor muscles have been identified in those with $\mathrm{CGH}$. This may contribute to muscular imbalance and susceptibility to injury in the cervical region. ${ }^{(27)}$ Within this UCMS, the sternocleidomastoid, upper trapezius, scaleni, and suboccipital muscle will present in a hypertonic state and shortened position.(23) The shortening and increased tone of the suboccipital muscles could result in prolonged neural tension through the myodural bridge. Prolonged muscle tone will lead to muscle dysfunctions such as trigger points. Trigger points are identified as a taut band within a muscle and have 
a characteristic "nodular" texture upon palpation.(28) When palpated, trigger points will elicit pain that can be felt locally or that can cause radiating pain.(29) Trigger points have been identified in those with

CGH in the upper trapezius, SCM, erector spinae, and suboccipital muscles. ${ }^{27,30)}$ Trigger points of the SCM can produce a unilateral referred pain over the forehead and around the ipsilateral eye and ear as seen in $\mathrm{CGH} .(31)$

It has been demonstrated that CGH is caused by dysfunction of the upper cervical spine. Due the soft tissue connection between muscle, cervical fascia and dura, this region might contribute to the development of CGH's. Therefore, it was the primary aim of this study to evaluate if subjects with CGH have concurrent neural tension signs. The secondary aim of this study was to investigate if there is a correlation between the position of atlas and mobility of atlantoaxial joint in those experiencing cervicogenic headaches compared to a healthy control group.

\section{Methods}

\section{Subjects}

A method of convenience sampling was used to recruit our subjects from a physical therapy clinic in Northwest Indiana. Based on a power analysis using a power of $80 \%$, alpha of 0.05 and an effect size of 0.4 it was determined to recruit 60 subjects for this study. All available subjects were screened for eligibility criteria. To participate, all subjects had to be between the ages of 18 and 65 , able to speak and read the English language fluently, have either cervicogenic headache or no experiences of headaches. The subjects in the CHG group had to have a neck disability index (NDI) greater than 15. In order to qualify for the non-headache control group, the subjects were not to have any cervical related diagnosis, neck pain, and or experience any headaches at the time of testing. The subjects were screened for any red flags and potential reasons why they could not undergo the testing protocol by the treating physical therapist. Additional exclusion criteria included: evidence of central nervous system involvement, including hyperreflexia, nystagmus, loss of visual acuity, impaired sensation of the face, altered taste, and the presence of pathological reflexes. This study received institutional review board (IRB) approval from Florida Gulf Coast University.

\section{Testing Protocol}

All 60 subjects ( 30 subjects in the CGH group and 30 subjects in the non-headache control group) were tested after giving written consent as part of their initial physical therapy evaluation. Each subjected completed the self-reported outcome measures first (VAS, NDI and HDI), after which the passive neck flexion rotation test measures and passive neural tension tests were randomly administered at the discretion of the physical therapist. The evaluating physical therapists were blinded to the results of the self-reported outcome measures. 


\section{Self-reported outcome measures}

Prior to the physical examination each subject completed the visual analog scale (VAS) to assess neck pain at the time of the evaluation.(32) Subjects marked their pain at the time of the initial evaluation on a 10-centimeter scale. On the left side of the scale is identified as "no pain at all" and the right side as "worst pain imaginable." The distance in millimeters from zero was recorded. The validity and reliability of the VAS for patients with acute and chronic pain has been reported as being good.(33) The Neck Disability Index (NDI) and the Headache Disability Inventory (HDI) were used as self-reported measures. The NDI is a 10-item patient self-reported measure that is used to measure each subjects level of reported disability. $(5,34-37)$ Higher scores on the NDI indicate greater disability levels.(38) Content, construct validity, and reliability of the NDI has been previously shown to be good in patients with neck pain.(34, 39) The HDI is a 25 -item patient self-reported measure evaluating the direct impact of headaches on daily living. Higher scores indicate higher impact. There are two scales, including 12 functional and 13 emotional items that combine for a maximum total score of 100 . Both the construct validity and the testretest reliability of the HDI has been demonstrated as being good.(40) The HDI is highly reliable with values ranging between 0.93 and 0.95.(40) The NDI has also been shown to have good content and construct validity and excellent test-retest reliability of 0.96.(40)

\section{Atlantoaxial range of motion assessment and atlas position}

All 60 subjects underwent an assessment of mobility of the upper cervical region. Atlanto-axial (AA) mobility was assessed in supine using the neck flexion-rotation test (FRT). During the FRT, the neck was placed in maximum forward bend position. At that point, rotation of the head in both directions was compared for range of motion measured with the goniometer, and assessed for the quality of endfeel. (41) The reliability of the FRT in patients with cervicogenic headaches has been demonstrated by Hall et al.(42) Based on a high sensitivity (90 to $91 \%$ ), specificity (88 to $90 \%$ ), and overall diagnostic accuracy $(91 \%)$ indicating that this an appropriate test to use clinically. $(42,43)$

The position of atlas relatively to the occiput was determined using direct palpation of the transverse process of atlas. The subjects were graded as neutral or "normal" position if there was no observable difference in position of bilateral transverse processes (TP) of the atlas. The TP's were palpated while the subjects were seated in a comfortable natural position while maintaining a protrusion of the mandible. The presence of a right atlas position default was assumed if there was a relative anterior position of the left transverse process compared to the right transverse process. A left atlas position default was assumed if there was a relative anterior position of the right transverse process compared to the left transverse process. The positional default position of atlas has been proposed previously ${ }^{44}$ and demonstrated to exist by using musculoskeletal ultrasound.(44)

\section{Assessment of neural tension}


Neural tension was assessed by using the slump test, upper limb tension test A (ULTT) and the straight leg raise test (SLR). All three tests are commonly used in the management of patients with musculoskeletal dysfunctions. The slump test was performed in sitting with the entire spine in a slumped position and the neck in maximal forward flexion. The subject's hands were positioned behind the pelvis. Starting with one knee at 90 degrees of flexion with maximal dorsal flexion of the ankle, the knee was actively extended to the point of discomfort. At this point, the subject actively extended the neck. The test was considered positive if the symptoms in the leg disappear. As a measurement of a positive slump test, the knee flexion angle provoking symptoms was measured. The slump test was than repeated on the other side. Intra-rater reliability has been reported as good with an ICC of 0.95.(45) Sensitivity and specificity of the slump test has been reports a being 0.84 and 0.83 respectively.(46)

The ULTT is a neural tension test carried out in the supine position. The subject's scapula was held in a somewhat depressed position by the physical therapist, while the following movements of arm are passively added until symptom reproduction occurred (shoulder abduction followed by forearm supination, wrist and finger extension, shoulder lateral rotation, and elbow extension). After this, passive cervical side bending to the contralateral side was added until symptoms occur. When there were symptoms, ipsilateral passive cervical side bending was added to decrease symptoms. The angle of elbow extension provoking pain and or symptoms served as the measure of a positive ULTT. The ULTT test has been identified as a good test to rule in neurotension with a specificity of 0.97 and an inter-rater reliability kappa value of 0.76 .(47)

The SLR test was carried out in the supine position. The subject fully extended the knee with the ankle in a neutral position. The physical therapist then passively flexed the hip while maintaining knee extension. A positive test is defined as reproduction of symptoms of pain and or tightness, subsiding on plantar flexion of the ankle. The angle of hip flexion was measured with a goniometer at the point symptoms began serving as the measure of a positive SLR. The sensitivity of the SLR has been reported at 0.87 and the specificity at $0.89 .(46,48)$

\section{Results}

Statistical analyses were performed using the SPSS, version 26.0, statistical software package. The data were analyzed for normal distribution using the Sharpo-Wilk test. The HDI and the neck flexion rotation test were normally distributed, so the independent $t$ test was used to determine the difference between the headache and the non-headache control group. The NDI, slump, ULTT, an the SLR were not normally distributed, therefore non-parametric statistics were used to analyze the data. (Table 1) 
Table 1

Test of Normality.

\begin{tabular}{|c|c|c|c|c|c|c|}
\hline \multicolumn{7}{|c|}{ Tests of Normality } \\
\hline & \multicolumn{3}{|c|}{ Kolmogorov-Smirnov ${ }^{a}$} & \multicolumn{3}{|c|}{ Shapiro-Wilk } \\
\hline & Statistic & df & Sig. & Statistic & df & Sig. \\
\hline NDI & .137 & 31 & .143 & .923 & 31 & .028 \\
\hline HDI & .113 & 31 & $.200^{*}$ & .978 & 31 & .755 \\
\hline VAS & .087 & 31 & $.200^{*}$ & .975 & 31 & .660 \\
\hline SlumpR & .473 & 31 & .000 & .495 & 31 & .000 \\
\hline SlumpL & .512 & 31 & .000 & .415 & 31 & .000 \\
\hline ULTTR & .458 & 31 & .000 & .351 & 31 & .000 \\
\hline ULTTL & .493 & 31 & .000 & .358 & 31 & .000 \\
\hline SLRR & .376 & 31 & .000 & .601 & 31 & .000 \\
\hline SLRL & .388 & 31 & .000 & .622 & 31 & .000 \\
\hline NFRTR & .124 & 31 & $.200^{*}$ & .978 & 31 & .757 \\
\hline NFRTL & .109 & 31 & $.200^{*}$ & .955 & 31 & .217 \\
\hline \multicolumn{7}{|c|}{ *. This is a lower bound of the true significance. } \\
\hline \multicolumn{7}{|c|}{ a. Lilliefors Significance Correction } \\
\hline
\end{tabular}

\section{Baseline characteristics}

A total of 60 subjects were assessed for eligibility and enrolled in the study. Twenty-six subjects were male (43.3\%) while 34 were female (56.7\%), and the mean subject age was 48.5 , with a range of 20 to 65 years. (Table 2 ). 
Table 2

Descriptive statistics study sample.

\begin{tabular}{|c|c|c|c|c|c|}
\hline \multicolumn{6}{|c|}{ Descriptive Statistics } \\
\hline & $\mathrm{N}$ & Minimum & Maximum & Mean & Std. Deviation \\
\hline Gender & 60 & 1.00 & 2.00 & 1.5667 & .49972 \\
\hline age & 60 & 20.00 & 65.00 & 48.4833 & 13.28245 \\
\hline condition & 60 & 1.00 & 2.00 & 1.5000 & .50422 \\
\hline HDI & 31 & .00 & 74.00 & 36.6452 & 17.74739 \\
\hline NDI & 31 & 14.00 & 56.00 & 29.7097 & 11.98664 \\
\hline VAS & 53 & .00 & 99.00 & 36.7170 & 29.58584 \\
\hline SlumpR & 60 & .00 & 27.00 & 2.6167 & 6.64370 \\
\hline SlumpL & 60 & .00 & 22.00 & 1.6333 & 4.71193 \\
\hline ULTTR & 60 & .00 & 90.00 & 3.1167 & 12.92494 \\
\hline ULTTL & 60 & .00 & 55.00 & 2.5667 & 8.42186 \\
\hline SLRR & 60 & 35.00 & 90.00 & 81.7167 & 14.78787 \\
\hline SLRL & 60 & 40.00 & 90.00 & 81.7000 & 13.75118 \\
\hline Atlas & 60 & 1.00 & 3.00 & 1.8333 & .76284 \\
\hline NFRTR & 60 & 15.00 & 70.00 & 34.6667 & 10.09223 \\
\hline NFRTL & 60 & 15.00 & 60.00 & 36.0000 & 9.82042 \\
\hline
\end{tabular}

\section{$\mathrm{CGH}$ and neck flexion rotation test}

To determine the difference in the neck flexion rotation test between the CGH headache group and the non-headache control group, cervical rotation range of motion in both groups was compared for each side separately. The independent $t$ test was utilized. There was a significant difference in the amount of passive $A A$ rotation to the right between the $\mathrm{CGH}(\mathrm{M}=31.77, \mathrm{SD}=6.7, \mathrm{SEM}=1.28)$ and the control group $(M=31.57, S D=11.87, S E M=2.17) ; t(58)=-2.306, p=0.025$. There was a difference in the amount of passive AA rotation to the left between the $\mathrm{CGH}(\mathrm{M}=33.77, \mathrm{SD}=9.53, \mathrm{SEM}=1.74)$ and the control group $(M=38.23, S D=9.75, S D=1.78)$ however this was not statistically significant; $t(58)=-1.794, p=0.078$.

\section{CGH and upper limb tension test}

To determine the difference in the upper limb tension between the CGH headache group and the nonheadache control group, the angle of elbow flexion in both groups was compared for each side separately. The Mann Whitney U test was utilized. There was no significant difference between the ULTT 
elbow flexion measurement on the right between the $\mathrm{CGH}$ and the control group: $U=413.5, \mathrm{p}=0.361$. There was no significant difference between the ULTT elbow flexion measurement on the left between the CGH and the control group: $U=424, p=0.515$.

\section{CGH and SLR test}

To determine the difference in the SLR test between the CGH headache group and the non-headache control group the angle of hip flexion in both groups was compared for each side separately. The Mann Whitney $U$ test was utilized. There was no significant difference between the passive SLR hip flexion measurement on the right between the $\mathrm{CGH}$ and the control group: $U=425, p=0.664$. There was no significant difference between the passive SLR hip flexion measurement on the left between the CGH and the control group: $U=422, p=0.627$.

\section{CGH and Slump test}

To determine the difference in the Slump test between the CGH headache group and the non-headache control group, the angle of knee flexion in both groups was compared for each side separately. The Mann Whitney $U$ test was utilized. There was no significant difference between the Slump knee flexion angle on the right between the $\mathrm{CGH}$ and the control group: $U=420, p=0.494$. There was no significant difference between the Slump knee flexion angle on the left between the $\mathrm{CGH}$ and the control group: $U=447, p=$ 0.940 .

\section{Correlation between outcome measures and neural tension testing}

To determine the correlation between the Neck flexion rotation test, ULTT, SLR, and the Slump test the Pearson Correlation was utilized. There was a small correlation between the Slump test and the ULTT (right $r=0.15$, left $r=0.23$ ). There was a medium correlation between the Slump test on the right and the SLR on the right; $r=-0.44$. There was a large correlation between the Slump test on the left and the SLR left; $r=-0.51$. There was a small correlation between The Neck flexion rotation test and the ULTT (right $r=$ 0.1 , left $r=0.23$ ) There was a small correlation with the Slump test on the right and no correlation on the left side (right $r=-0.1$, left $r=0.03$ ). There was a small correlation with the SLR test (right $r=-0.21$ and left $r=-0.31$ ). The results of the HDI were not related with the Neck flexion rotation test (right $r=0.04$, left $r=$ 0.08). There was a small correlation with the Slump test on the right $(r=-0.252)$ and no correlation on the left $(r=0.02)$. There was a small correlation with the ULTT (right $r=-0.22$, left $r=-0.308$ ). There was a small correlation with the SLR (right $r=-0.291$, left $r=-0.184$ ). There was a small correlation between the NDI and the HDI $(r=0.196)$

\section{Correlation between Atlas position and CHG, and NFRT}

To determine if the position of atlas was correlated with the presence of CHG's, the chi-square test of independence was performed. The relationship between the atlas position and CGH was significant, $\mathrm{X}^{2}=$ 20.526, $\mathbf{P}<0.001$. Subjects with a rotated atlas upon palpation were more likely to experience $\mathrm{CGH}$. 
To determine the relationship between atlas position and the mobility of the AA joints test through the Neck flexion rotation test the Kruskal-Wallis test was performed. It appears that atlas position significantly affects the AA mobility measured in the NFRT, $H(2)=18.55, p<0.001$. (Table 3 )
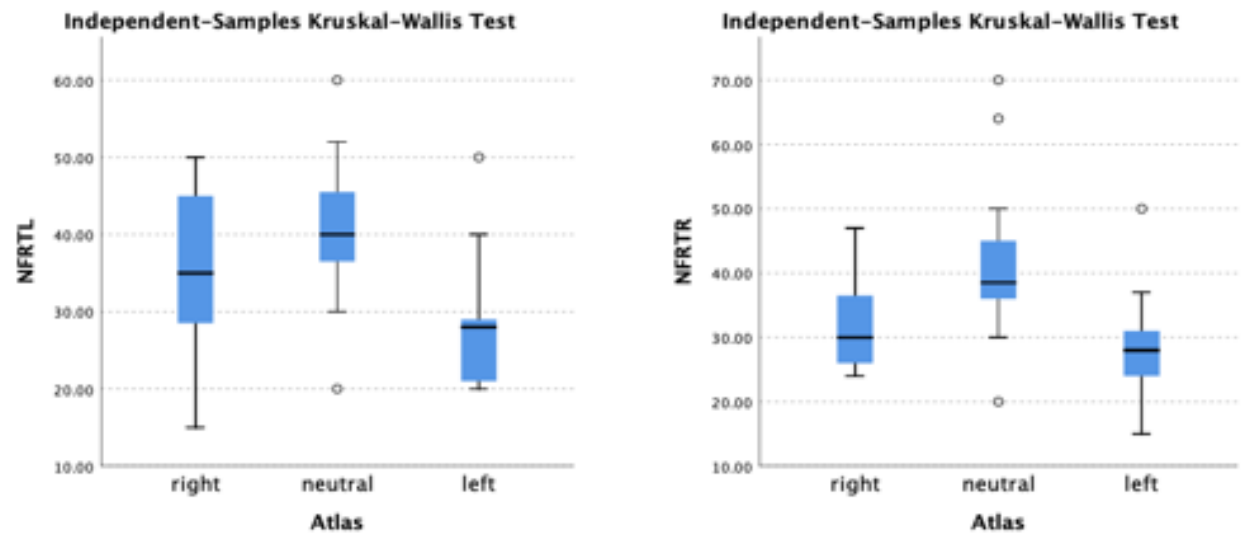

Table 3

Kruskal-Wallis results: atlas position related to AA mobility

\section{Discussion}

The primary aim of this study was to evaluate if subjects with CGH have concurrent neural tension signs. The secondary aim was to investigate if the there is a correlation between the position of atlas and mobility of atlantoaxial joint in those experiencing cervicogenic headaches compared to a healthy control group. Cervicogenic headache has been defined as a headache which is the resultant of a cervical related dysfunction and perceived in 1 or more regions in the head and/or face.(8) The current rationale explaining the mechanism how CGH develops is through the neurogenic relationship between the spinal nerves $\mathrm{C} 1$ through $\mathrm{C} 3$ and the trigeminal nerve at the trigeminocervical nucleus. $(14,15)$ This is where the nociceptive signals of the upper cervical joints will converge with the trigeminal second order neuron and thus could result in sensitization of the trigeminal nerve. The cervical segments below C3 have not shown to radiate toward any region of the head.(49) The results of this study support this notion that the spinal segments below C4 do not contribute to the development of CGH's. The ULTT places the C5-T1 cervical nerve roots under direct tension. This study demonstrates a weak and non-significant relationship between CGH's and the ULTT.

Menigiovertebral connections have been identified all throughout the spinal column.(50) It has been hypothesized that the function of the menigiovertebral bridge is to maintain position of the spinal cord within the spinal canal during motion in such a way that there will be no pinching or compression of the cord during movement of the neck and head. The motion of the suboccipital region is controlled by several groups of both smaller and larger muscles. The suboccipital muscles are part of the complex control mechanism allowing motion of atlas relative to axis. During neck rotation the head moves relatively on the neck allowing atlas to turn on axis through the unilateral contraction of the Rectus 
capitis major and the obliques capitis inferior. Myodural bridges in the upper cervical spine between the rectus capitis major and the obliquus capitis inferior muscles and the dura have been identified, however the true clinical relevance remain elusive. $(50,51)$ When the head is turned the myodural bridge will pull the dura mater ipsilaterally. This could lead to increased dural tensioning. This tension might play a role in the development of CGH's. The results of this study support this possible secondary pathway of developing CGH as the NFRT and the position of atlas were directly related to the presence of CGH.

It has been previously demonstrated that abnormal cervical functioning will change the proprioceptive awareness coming from this region.(17) Proprioception is the information sent by mechanoreceptive neurons to the brain, informing it of the position of the neck, head, and any positional changes. There is an exceptionally high density of these neurons in the suboccipital muscles located in the posterior upper cervical spine.(17) Abnormal proprioception will lead to abnormal muscle tone. If suboccipital muscle contraction or tonicity is maintained for prolonged period of time this could result in a change in positional relationships between segments of the upper cervical spine. Such positional default in a subject with CGH has been previously suggested and confirmed with musculoskeletal ultrasound imaging by Sillevis and Swanick.(44) In this study palpation was used to identify the relative position of atlas and the results of this study support the notion that a positional default of atlas in subjects with $\mathrm{CGH}$ was present. If a positional default position is a contributing factor in the development of CGH cannot be determined based on this study. However, it can be hypothesized that an increase in muscle tightness would result in decreased mobility. The result of this study supports this notion as the CHG group had a significant decreased right rotation of the atlantoaxial joint compared to the control group. There was a difference but not significant with left rotation. The inter and intra rater reliability of palpation for position of the atlas has not been reported previously and this could have been a limiting factor in this study.

Scali et al(18) and Pontel et al(19) previously suggested that increased tension of the suboccipital muscles could lead to $\mathrm{C} 2$ nerve tension due to the presence of the myodural bridge. Due to these fascialike connections muscle tone could affect the functioning of the dura and possibly negatively affect dural mobility. Neural tensions tests are clinically used to identify if movement of neural tissues is normal by progressively increasing the pull on these tissues. If there are limitations in neural mobility direct pull will provoke patient related symptomology. In this study, we used the bilateral ULTT, Slump test and the SLR tests bilaterally to tests if neural mobility was restricted in subjects with CGH. It appears that results of this study cannot support the do not support the notion that there is restricted mobility in the upper cervical dura. This study demonstrated that there was a weak correlation between the ULTT and the presence of $\mathrm{CGH}$. However, this could be explained by the fact that the nerves that make up the brachial plexus leave the spinal cord below the C4 level. The slump test and the SLR test were used to load the nervous system in the sagittal plane from head to toe. There was no significant relationship identified between CGH and either the Slump and or the SLR test. What was not surprising was that there is a medium to large correlation between the slump tests and the SLR test supporting the thought that both tests have a similar effect of the dura. The fact that both the Slump and the SLR do not correlate with $\mathrm{CGH}$ might be due to the fact the menigiovertebral bridges in the lumbar and thoracic spine and might 
prevent direct pull on the upper cervical dural movement.(50) Based on the fact that there were only small correlations between the ULTT, Slump test, the SLR test and CGH's one can conclude that the pathophysiology resulting in $\mathrm{CGH}$ is located in the upper cervical region.

This study has several limitations. It is possible that the non-headache control group had musculoskeletal conditions that could have directly affected the mobility of the nervous system and thus effected the neural tension tests. Another limitation that could have affected the outcome of this study is the fact that we did not identify if the subject were right or left-handed. This might coincide with preference of neuromuscular pathways in the high cervical spine and thus effect AA mobility and therefore effect dural tension. Our subjects were not assessed for forward head posture. This position could lead to a posterior rotation of the occiput on the atlas in the sagittal plane. This will place the suboccipital muscles and the posterior neck muscles in a shortened position and this could result in muscle hypertrophy. The presence of the myodural bridge might than result in direct neural tension and could have affected the NFRT mobility testing. $(50,52)$

\title{
Conclusion
}

The results of this study demonstrate that there is a direct relationship between the position of atlas, unilateral restriction in AA rotation, and the presence of CGH's. The presence of fascial connections between structures of the high cervical spine and the dura motion could result in dural tension and should be considered by physical therapists when managing patients with CGH. The use of the ULTT, Slump test, and SLR test do not appear beneficial identifying those with CGH. Further research is necessary to evaluate the relationship and clinical relevance of the myodural bridge in the upper cervical spine and the possible causative relationship of this on the development of $\mathrm{CGH}$.

\section{List Of Abbreviations}

\author{
AA-Atlantoaxial
}

CGH-cervicogenic headaches

FRT-Flexion Rotation test

HDI-Headache disability index

IRB-Institutional review board

NDI- Neck disability index

SCM-Sternocleidomastoid muscle

SLR-Straight leg raise test 
TP-transverse process

VAS-Visual analogue scale

UCMS-Upper cross muscle syndrome

ULTT-Upper limb tension test

\section{Declarations}

\section{Ethical Approval and Consent to participate}

Ethics approval for this study was obtained from the institutional review board at Florida Gulf Coast university, FL, USA and all subjects provided written consent to participate in this study.

\section{Consent for publication}

The authors give consent to the journal of Headache and Pain consent to publish this article and use the details/images. We consent to the fact that this article and its content will be freely available on the internet and may be seen by the general public.

\section{Availability of supporting data}

All data generated or analyzed during this study are included in this published article [and its supplementary information files].

\section{Competing interests}

The authors declare that they have no competing interests for this study.

\section{Funding}

The authors declare that they did not receive any funding for this study.

\section{Authors' contributions}

Rob Sillevis made substantial contributions to the conception and design of this work. He performed the data analysis and drafted the manuscript. He approved the submitted version and has agreed both to be personally accountable for the author's own contributions and to ensure that questions related to the 
accuracy or integrity of any part of the work, even ones in which the author was not personally involved, are appropriately investigated, resolved, and the resolution documented in the literature.

Eric Shamus made substantial contributions to the conception and design of this work. He approved the submitted version and approves and has agreed both to be personally accountable for the author's own contributions and to ensure that questions related to the accuracy or integrity of any part of the work, even ones in which the author was not personally involved, are appropriately investigated, resolved, and the resolution documented in the literature.

Karen Wyss collected the data and made substantial contributions to the conception and design of this work and has agreed both to be personally accountable for the author's own contributions and to ensure that questions related to the accuracy or integrity of any part of the work, even ones in which the author was not personally involved, are appropriately investigated, resolved, and the resolution documented in the literature

\section{Acknowledgements}

Not applicable

\section{References}

1. Strine T, Hootman J. US National prevelance and correlations of low back and neck pain among adults. Arthritis \& Rheumatism (Arhtritis Care \& Research). 2007;57(4):656-65.

2. Taylor $\mathrm{H}$, Murphy B. Altered sensorimotor integration with cervical spine manipulation. Journal of Manipulative and Physiological Therapeutics. 2008;31(2):116-25.

3. Gross A, Hoving J, Haines T, Goldsmith C, Kay T, Aker P, et al. A cochrane review of manipulation and mobilization for mechanical neck disorders. Spine. 2004;29(14):1541-8.

4. Gross A, Kay T, Hondras M, Goldsmith C, Haines T, Peloso P, et al. Manual therapy for mechanical neck disorders: a systematic review. Manual Therapy. 2002;7(3):131-49.

5. Tseng Y, Wang W, Chen W, Hou T, Chen T, Lieu F. Predictors for immediate responders to cervical manipulation in patients with neck pain. Manual Therapy. 2006;11:306-15.

6. Bogduk N. Innervation and Pain patterns of the Cervical Spine. Clinics in Physical Therapy: Physical Therapy of the Cervical and Thoracic Spine New York: Churchill Livingstone; 1994. p. 65-76.

7. Krauss J, Creighton D, Ely J, Podlewska-Ely J. The immediate effects of upper thoracic translatoric spinal manipulation on cervical pain and range of motion: A randomized clinical trial Journal of Manual and Manipulative Therapy. 2008;16(2):93-9.

8. The International Classification of Headache Disorders: 2nd edition. Cephalalgia. 2004;24 (suppl 1):9-160. 
9. Nilsson N. The prevalence of cervicogenic headache in a random population sample of 20-59 year olds Spine. 1995;20:1884-8.

10. Sjaastad O, Bakketeig L. Tension-type headache: Comparison with migraine without aura and cervicogenic headache. The Vaga study of headache epidimiology. Functional Neurology. 2008;23(2):71-6.

11. Sjaastad O, Bakketeig L. Prevelance of cervicogenic headache: VAGA study of hedache epidemiology. Acta Neurol Scand. 2008;117:173-80.

12. Haldeman S, Dagenais S. Cervicogenic headaches: a critical review. The Spine Journal. 2001;1:3146.

13. Aprill C, Axinn M, Bogduk N. Occipital headcahes stemming from the lateral atlanto-axial (C1-2) joint. Cephalalgia. 2002;22:15-22.

14. Hall T, Briffa K, Hopper D. Clinical evaluation of cervicogenic headache: a clinical perspective. J Man Manip Ther. 2008;16(2):73-80.

15. Biondi DM. Cervicogenic headache: diagnostic evaluation and treatment strategies. Curr Pain Headache Rep. 2001;5(4):361-8.

16. Bogduk N. The neck and headaches. Neurol Clin. 2014;32(2):471-87.

17. Roijezon U, Clark NC, Treleaven J. Proprioception in musculoskeletal rehabilitation. Part 1: Basic science and principles of assessment and clinical interventions. Man Ther. 2015;20(3):368-77.

18. Scali F, Marsili ES, Pontell ME. Anatomical connection between the rectus capitis posterior major and the dura mater. Spine (Phila Pa 1976). 2011;36(25):E1612-4.

19. Pontell ME, Scali F, Marshall E, Enix D. The obliquus capitis inferior myodural bridge. Clin Anat. 2013;26(4):450-4.

20. Szikszay TM, Luedtke K, Harry von P. Increased mechanosensivity of the greater occipital nerve in subjects with side-dominant head and neck pain - a diagnostic case-control study. J Man Manip Ther. 2018;26(4):237-48.

21. Caamano-Barrios LH, Galan-Del-Rio F, Fernandez-de-Las-Penas C, Cleland JA, Plaza-Manzano G, Ortega-Santiago R. Evaluation of neurodynamic responses in women with frequent episodic tension type headache. Musculoskelet Sci Pract. 2019;44:102063.

22. von Piekartz HJ, Schouten S, Aufdemkampe G. Neurodynamic responses in children with migraine or cervicogenic headache versus a control group. A comparative study. Man Ther. 2007;12(2):153-60.

23. Moore MK. Upper crossed syndrome and its relationship to cervicogenic headache. J Manipulative Physiol Ther. 2004;27(6):414-20.

24. Biondi DM. Noninvasive treatments for headache. Expert Rev Neurother. 2005;5(3):355-62.

25. Bogduk N, Govind J. Cervicogenic headache: an assessment of the evidence on clinical diagnosis, invasive tests, and treatment. Lancet Neurol. 2009;8(10):959-68.

26. Fernandez-de-Las-Penas C, Ge HY, Arendt-Nielsen L, Cuadrado ML, Pareja JA. Referred pain from trapezius muscle trigger points shares similar characteristics with chronic tension type headache. 
Eur J Pain. 2007;11(4):475-82.

27. Petersen SM. Articular and muscular impairments in cervicogenic headache: a case report. J Orthop Sports Phys Ther. 2003;33(1):21-30; discussion -2.

28. Schneider MJ. Tender points/fibromyalgia vs. trigger points/myofascial pain syndrome: a need for clarity in terminology and differential diagnosis. J Manipulative Physiol Ther. 1995;18(6):398-406.

29. Fernandez-de-Las-Penas C, Ge HY, Alonso-Blanco C, Gonzalez-Iglesias J, Arendt-Nielsen L. Referred pain areas of active myofascial trigger points in head, neck, and shoulder muscles, in chronic tension type headache. J Bodyw Mov Ther. 2010;14(4):391-6.

30. Huber J, Lisinski P, Polowczyk A. Reinvestigation of the dysfunction in neck and shoulder girdle muscles as the reason of cervicogenic headache among office workers. Disabil Rehabil. 2013;35(10):793-802.

31. Missaghi B. Sternocleidomastoid syndrome: a case study. J Can Chiropr Assoc. 2004;48(3):201-5.

32. Bird S, Dickson E. Clinically significant changes in pain along the visual analoge scale. Annals of Emergency Medicine. 2001;38(6):639-43.

33. Gallagher E, Liebman M, Bijur P. Prosepctive validation of clinically important changes in pain severity measured on a visual analoge scale. Annals of Emergency Medicine. 2001;38(6):633-8.

34. Vernon H, Mior S. The Neck Disability Index: a study of reliability and validity. Journal of Manipulative and Physiological Therapeutics. 1991;14:409-15.

35. Childs J, Cleland J, Elliot J, Teyhen D, Wainner R, Whiteman J, et al. Neck Pain: Clinical practice guidelines linked to the international classification of functioning, disability, and health From the Orthopaedic Section of the American Physical Therapy Association. Journal of Orthopaedic \& Sports Physical Therapy. 2008;38(9):A1-A34.

36. Cleland JA, Childs JD, McRae M, Palmer JA, Stowell T. Immediate effects of thoracic manipulation in patients with neck pain: a randomized clinical trial. Man Ther. 2005;10(2):127-35.

37. Riddle D, Stratford P. Use of generic versus region-specific functional status measures on patients with cervial spine disorders. Physical Therapy. 1998;78:951-63.

38. Cleland J, Fritz J, Whitman J, Palmer J. The reliability and construct validity of the neck disability index and patient specific functional scale in patients with cervical radiculopathy. Spine. 2006;31:598-602.

39. Hoving J, O'Leary E, Niere K, Green S, Buchbinder R. Validity of the neck disability index, Northwick Park neck pain questionnaire, and problem elicitation technique for measuring disability associated with whiplas-associated disorders. Pain. 2003;102:273-81.

40. Jacobson GP, Ramadan NM, Norris L, Newman CW. Headache disability inventory (HDI): short-term test-retest reliability and spouse perceptions. Headache. 1995;35(9):534-9.

41. Piva SR, Erhard RE, Childs JD, Browder DA. Inter-tester reliability of passive intervertebral and active movements of the cervical spine. Man Ther. 2006;11(4):321-30. 
42. Hall TM, Robinson KW, Fujinawa $O$, Akasaka K, Pyne EA. Intertester reliability and diagnostic validity of the cervical flexion-rotation test. J Manipulative Physiol Ther. 2008;31(4):293-300.

43. Ogince $M$, Hall $T$, Robinson $K$, Blackmore AM. The diagnostic validity of the cervical flexion-rotation test in C1/2-related cervicogenic headache. Man Ther. 2007;12(3):256-62.

44. Sillevis R, Swanick K. Musculoskeletal ultrasound imaging and clinical reasoning in the management of a patient with cervicogenic headache: a case report. Physiother Theory Pract. 2019:1-11.

45. Tucker N, Reid D, McNair P. Reliability and measurement error of active knee extension range of motion in a modified slump test position: a pilot study. J Man Manip Ther. 2007;15(4):E85-91.

46. Majlesi J, Togay H, Unalan H, Toprak S. The sensitivity and specificity of the Slump and the Straight Leg Raising tests in patients with lumbar disc herniation. J Clin Rheumatol. 2008;14(2):87-91.

47. Wainner RS, Fritz JM, Irrgang JJ, Boninger ML, Delitto A, Allison S. Reliability and diagnostic accuracy of the clinical examination and patient self-report measures for cervical radiculopathy. Spine (Phila Pa 1976). 2003;28(1):52-62.

48. Jonsson B, Stromqvist B. The straight leg raising test and the severity of symptoms in lumbar disc herniation. A preoperative evaluation. Spine (Phila Pa 1976). 1995;20(1):27-30.

49. Becker WJ. Cervicogenic headache: evidence that the neck is a pain generator. Headache. 2010;50(4):699-705.

50. Scali F, Pontell ME, Nash LG, Enix DE. Investigation of meningomyovertebral structures within the upper cervical epidural space: a sheet plastination study with clinical implications. Spine J. 2015;15(11):2417-24.

51. Shi B, Zheng X, Min S, Zhou Z, Ding Z, Jin A. The morphology and clinical significance of the dorsal meningovertebra ligaments in the cervical epidural space. Spine J. 2014;14(11):2733-9.

52. Enix DE, Scali F, Pontell ME. The cervical myodural bridge, a review of literature and clinical implications. J Can Chiropr Assoc. 2014;58(2):184-92. 